Resenha

\title{
Trabalho e desgaste mental: o direito de ser dono de si mesmo
}

\author{
SELIGMANN-SILVA, Edith. São Paulo: Cortez, 2011. 624 p. ISBN 9788524917561
}

Este livro tem uma linguagem clara e compreensível, mesmo para os leitores que não estejam habituados com as múltiplas disciplinas que têm interface com o que a autora designa Campo Ampliado da Saúde Mental Relacionada ao Trabalho. Percebe-se que a autora, ao compreender que a saúde mental não mais é assunto de atenção somente das áreas profissionais da Psiquiatria e da Psicologia, faz questão de se fazer entender por todos que o folheiem. Outra característica do livro é a vastidão da temática exposta. Trata-se também de um livro denso e que, ao escapar das abordagens convencionais, assume uma perspectiva crítica. São oito partes e dezoito capítulos cujos temas e subtemas são detalhados no índice e cuidadosamente articulados e aprofundados no texto, refletindo tanto uma rara erudição, como a insubstituível experiência acumulada ao longo de mais de três décadas de estudos e pesquisas acerca dos contextos de adoecimento dos trabalhadores. O que poderia ser um grave problema transforma-se, assim, em virtude.

A parte I do livro, com seus três capítulos, faz um histórico da evolução dos estudos sobre transtornos mentais, apresenta as disciplinas que contribuem e fornecem elementos para a construção do Campo Ampliado da Saúde Mental Relacionada ao Trabalho e discute seus principais referenciais teóricos. A autora relembra que, até os anos 1970, a maioria dos estudos reconhecia o trabalho apenas como um fator desencadeante de transtornos mentais que já estavam predefinidos pelas "estruturas de personalidade" e pelos aspectos genéticos, compreendidos, até então, como principais determinantes do modo de adoecimento. Embora houvesse uma Psiquiatria Social em desenvolvimento, os aspectos do trabalho não eram enfatizados até então, com exceção da produção de poucos autores. Destaca alguns estudos pioneiros e disciplinas que contribuíram para uma ampliação da compreensão do processo de adoecimento mental dos trabalhadores submetidos a determinadas situações de trabalho. Cita, assim, o psiquiatra francês Louis Le Guillant como a pessoa que construiu a ponte entre a Psiquiatria e a Psicopatologia do Trabalho. Dos anos 1940 a 1960, ao observar o papel do trabalho na reestruturação psíquica e na reintegração social dos pacientes psiquiátricos hospitalizados, Le Guillant conseguiu descobrir o potencial patogênico de certas situações laborais. A autora destaca dois de seus estudos dentre sua produção sobre Psicopatologia no Trabalho: a pesquisa sobre telefonistas e mecanógrafos e outra sobre empregadas domésticas. Fala também sobre as apro- ximações e interfaces construídas entre a Psicologia do Trabalho, inicialmente focada na seleção de pessoal, e a Psicologia Social, na qual se insere com a Sociologia do Trabalho, com a Psicologia Organizacional e com a Ergonomia. Discorre sobre o papel da Psicanálise na construção de suportes teóricos da Saúde Mental Relacionada ao Trabalho, particularmente da Psicodinâmica do Trabalho, assim como sobre as confluências com a Antropologia, os estudos sobre a organização do trabalho, as abordagens voltadas à Saúde do Trabalhador, a Epidemiologia e, ainda, alguns aspectos da Neurologia e da Neurociência.

O terceiro capítulo da parte I, que trata dos referenciais teóricos, ressalta três correntes, quais sejam a teoria do estresse, a fundamentada no referencial psicanalítico e a teoria do desgaste mental que parte do conceito de desgaste elaborado por Asa Cristina Laurell. Esta última é considerada pela autora como visão integradora de aspectos ambientais, psicossociais e intrapsíquicos, abrangendo contextos de trabalho, relações de poder e impactos mentais que atingem, entrelaçadamente, a inteligência e a afetividade (sentimentos e emoções). A concepção de desgaste mental permitiria, assim, entender as fontes e a articulação entre diferentes processos que acarretam o desgaste mental em suas três dimensões: orgânica, funcional e relativa à vida mental, isto é, à subjetividade. Aponta a necessidade de se escapar das armadilhas reducionistas, como as interpretações que enfatizam fatores e não enxergam os processos que engendram desgaste e adoecimento. Sugere, ainda, que se tente integrar as diferentes correntes em busca de metodologias que consigam auxiliar na compreesão dos inúmeros prismas das situações concretas de trabalho e dos processos que incidem sobre a saúde mental e afetam os mecanismos da estabilidade psicossomática.

A parte II do livro dá uma visão panorâmica do mundo do trabalho ao longo da história, e de como as formas de dominação foram se modificando junto com as transformações das relações sociais do trabalho, da tecnologia dos processos de produção e da organização e gestão do trabalho.

A parte III do livro trata da dominação dos que trabalham não só nos locais formalmente designados para tal, mas em todos os espaços de sua existência. A autora cita estudos que abrangem o contexto das mudanças políticas e socioeconômicas e suas repercussões sobre as situações de trabalho nos aspectos nocivos à 
saúde dos trabalhadores, incluindo a esfera psíquica. No primeiro caítulo desta parte do livro, para situar os estudos acerca de dominação e resistência dos "dominados" no Brasil, remete à escravidão dos negros africanos e dos indígenas pelos portugueses e a dificuldade de união e organização de formas de resistência devido à grande diversidade cultural.

Particularmente, das partes IV a VII do livro, utilizando-se de pesquisas realizadas, de sua experiência e de um vasto levantamento bibliográfico, a autora retoma e renova tópicos de seu livro Desgaste Mental no Trabalho Dominado, publicado em 1994. Destaca-se entre seus vários capítulos, o Capítulo II da parte IV, que trata da análise da dimensão psíquica referente aos acidentes do trabalho, no qual a autora enfoca o importante papel do desgaste mental, cognitivo e psicoafetivo, no que chama de "trama causal dos acidentes de trabalho", discutindo, ainda, as repercussões psíquicas decorrentes desses eventos e sobre as dificuldades em tê-las reconhecidas como relacionadas ao trabalho. Neste capítulo em particular, destaca a ausência do cuidado de prevenção de transtornos pós-traumáticos em nosso país.

Na parte V, a autora analisa a interface família-trabalho em vários aspectos, incluindo as repercussões de acidentes de trabalho sobre a dinâmica familiar. A condição feminina no mundo do trabalho formal e informal, as desvantagens de salário, de posição hierárquica e de reconhecimento e valorização social em relação aos homens são temas que mereceram destaque, sendo citadas pesquisas no campo da Sociologia do Trabalho, nas quais foram identificadas relações de poder e preconceitos que desfavorecem as mulheres e nas quais se assinalam repercussões negativas para a saúde mental.

Na parte VI, cujo enfoque é dado às representações e às percepções dos trabalhadores sobre o trabalho, são analisadas manifestações verbais de trabalhadores de diversas categorias profissionais cuja identidade se confunde com elementos de suas atividades laborais, como, por exemplo, no chamado "trabalho sujo" em que tratam de dejetos e percebem-se tratados como se também o fossem. São descritos mecanismos protetores da estrutura psíquica por meio de condições e suportes sociais, ao mesmo tempo em que são analisados contextos favoráveis e desfavoráveis para a construção de resistências coletivas.

A parte VIII do livro é designada "Metamorfoses Articuladas: sofrimento social, trabalho e desgaste mental”. Nesta parte, a autora discorre de forma aprofundada sobre as metamorfoses do desgaste humano no sistema neoliberal dos séculos XX e XXI, passando, no primeiro capítulo, pelo tema da Psicopatologia do Trabalho nas situações de recessão e no desemprego. O segundo capítulo ilumina um assunto de grande atualidade que é o da precarização da saúde mental no contexto da precarização social e do trabalho. No terceiro capítulo desta última parte, a autora lembra que a violência é considerada um problema de saúde pública pela Organização Mundial de Saúde e analisa os diversos aspectos que representam os pilares das formas de violência do mundo do trabalho contemporâneo e o processo atual de produção das expressões clínicas do desgaste mental e do adoecimento nesse cenário. Examina transtornos psíquicos relacionados ao trabalho, como transtorno de estresse pós-traumático, depressão, esgotamento profissional ou burnout, entre outros, mencionando ainda os suicídios.

Comparado ao seu livro Desgaste Mental no TrabaIho Dominado (1994), em cada um dos temas e enfoques que são retomados, o texto torna nítidas as transformações acarretadas pelas mudanças políticas, econômicas e do próprio conhecimento da temática. É indiscutível a imensa metamorfose das situações sociolaborais que engendram a expansão dos desgastes humanos relacionados ao trabalho. Da mesma forma, é notável o precioso enriquecimento da análise que a autora proporciona nesta nova obra. Embora claramente partidária da teoria do desgaste, vinculada ao método dialético, de maneira generosa e propositiva, ao falar sobre os resultados de estudos realizados à luz de diferentes referenciais teóricos das principais correntes do campo da saúde mental relacionada ao trabalho, a autora consegue reconhecer contribuições como a identificação de aspectos que merecem ser incorporados nas análises das diferentes situações laborais e dos processos de produção do adoecimento psíquico.

Passados 17 anos da publicação de seu livro anterior, a autora aprofunda sua análise do mundo do trabalho, que sofre constante e continuamente mudanças sob preocupante apagamento ético, mantendo os trabalhadores sob pressão que os leva ao acirramento competitivo que na atualidade dilacera laços sociais e afetivos em todos os patamares e ambientes de trabalho e de vida. Retrata, assim, os meandros de um proces so crescente de precarização, marcado pelo subemprego e pela instabilidade dos que vivem de salários, mesmo em contextos de crescimento econômico, como é o caso do nosso país, em que o crescimento não tem trazido contrapartidas de aumento de dispositivos legais, institucionais e culturais significativas para a promoção da saúde e a proteção do meio ambiente.

Adicionalmente, é importante estar atento para o que se passa na geopolítica e na macroeconomia mundiais, tendo em vista que essas tendências poderão afetar o nosso país. O Diretor-geral da Organização Internacional do Trabalho, em matéria publicada no jornal $O$ Estado de São Paulo, de 2 de novembro de 2011 (SOMAVIA, 2011), começa dizendo que "o panorama mundial de emprego é terrível”, afirmando que o desemprego afeta mais de duzentos milhões de pessoas e continua aumentando. Chama a atenção para o fato de que essa cifra não inclui os milhões de pessoas que vivem em subempregos e no mercado informal. Destaca o desemprego entre jovens, duas ou três vezes superior ao dos adultos. Alerta que podemos entrar em uma recessão de uma década, tendo em vista a desaceleração da economia desde meados de 2011. Também no Brasil, segundo o Departamento Intersindical de Estatística e Estudos 
Socioeconômicos - Dieese (WARTH, 2011), a crise financeira já altera a taxa de ocupação em nosso país, que caiu nas sete regiões metropolitanas pesquisadas pelo órgão nas comparações com o mesmo mês do ano anterior, de 5,5\% em 2010 para menos de 2\% este ano, assim como a renda que parou de crescer. Dessa forma, o capítulo um da parte VIII do livro, que trata do desgaste mental nas crises econômicas, adquire uma particular importância neste momento da história.

A parte final da obra formula reflexões reportadas aos desafios identificados e discute algumas perspectivas de enfrentamento e superação, tanto no campo social, quanto no clínico, mas passando, necessariamente, por uma reabilitação ética que permita resgatar o respeito à condição humana e aos direitos que lhe são inerentes, e construir políticas públicas capazes de superar o leque de precarizações apontadas pelo livro, assim como de oferecer uma clínica contextualizada do trabalho, na qual sejam possíveis a prevenção do desgaste humano e a reabilitação da legião de adoecidos. A autora do livro, Edith Seligmann-Silva, é psiquiatra e pioneira dos estudos sobre saúde mental relacionada ao trabalho no Brasil. Foi professora do Departamento de Medicina Preventiva da Faculdade de Medicina da Universidade de São Paulo de 1973 a 1996 e do Departamento de Fundamentos Sociais e Jurídicos da Administração da Escola de Administração de Empresas de São Paulo da Fundação Getúlio Vargas, de 1992 a 2006. Tem grande experiência clínica e também especialização em Saúde Pública. Entre as diversas frentes de atuação, esteve à frente da elaboração e supervisão de programação de Saúde Mental na rede estadual de centros de saúde pela Secretaria de Estado da Saúde de São Paulo, de 1976 a 1978. Atualmente aposentada, continua trabalhando em projetos de pesquisa. É parecerista de diversas revistas científicas e possui uma agenda intensa entre estudos, palestras, aulas e entrevistas.

Como médica sem formação especializada em Psiquiatria, ao ler o livro que ora tenho o prazer de resenhar, encontrei um mundo de explicações, reflexões e provocações que buscava para minhas indagações acumuladas no decorrer de mais de vinte anos de atuação na área da
Saúde do Trabalhador. Creio que todos os que lerem terão esse gratificante retorno. Particularmente os profissionais de saúde e da assistência social que acolhem pessoas que vivem do trabalho ou que procuram emprego poderão ter, com riqueza de detalhes, um cenário do mundo do trabalho atual e as profundas marcas sobre a saúde e o bem-estar dos trabalhadores e de suas famílias, compreendendo o processo de desgaste físico e psíquico por que passam. Os profissionais de saúde mental, em particular, que prestam assistência a pacientes com diagnósticos variados, muitas vezes sem se atentarem para a causalidade ocupacional, encontrarão sólidas fundamentações que lhes trarão outras perspectivas de atuação. Também os pesquisadores das áreas da sociologia do trabalho, filosofia, antropologia e direito encontrarão muitos elementos para a interlocução necessária com o campo da saúde. Os profissionais de segurança e saúde no trabalho das empresas certamente poderão encontrar caminhos a serem trilhados no difícil papel que lhes é atribuído, o de administrar questões referentes à proteção da vida e da saúde dos trabalhadores, sem terem a suficiente autonomia e integração com o sistema de produção para de fato promoverem alterações nas condições e organização do trabalho. E finalmente os gestores das empresas, focados no desempenho e na imagem no mercado de trabalho, poderão ser despertados para o fato de que os trabalhadores devem ser considerados na sua integralidade, pois, ao contrário de máquinas, os seres humanos são providos da subjetividade, fundamental na capacidade de pensar, criar e trabalhar.

\section{Referências}

SOMAVIA, J. Crise mundial do emprego. O Estado de S. Paulo, São Paulo, 2 nov. 2011. p. A2.

WARTH, A. Crise já afeta comportamento do desemprego, diz Dieese. O Estado de S. Paulo, São Paulo, 29 set. 2011. Disponível em: < http://agencia. ipea.gov.br/index.php?option $=$ com_content\&view $=$ art icle\&id $=10722 \&$ catid $=159 \&$ Itemid $=75>$. Acesso em: 2 nov. 2011. 